\title{
Eles devoraram tudo: primitivismo, barbárie e as vanguardas
}

\author{
[ They have devoured everything: primitivism, barbarism and the avant-gardes
}

\author{
Bruna Della Torre de Carvalho Lima ${ }^{\mathrm{I}}$
}

Este artigo é resultado da minha pesquisa de mestrado sob a orientação da profa. dra. Lilia Katri Moritz Schwarcz junto ao Departamento de Antropologia da Faculdade de Filosofia, Letras e Ciências Humanas da Universidade de São Paulo, que contou com o apoio financeiro da Fundação de Amparo à Pesquisa do Estado de São Paulo - Fapesp.

\begin{abstract}
RESUMO - O primitivismo é um aspecto fundamental do modernismo brasileiro e encontra na obra de Oswald de Andrade uma das suas mais importantes expressões. A "Poesia Pau Brasil" e a "antropofagia" mobilizavam o primitivismo para, como dizia Oswald de Andrade, acertar os ponteiros da literatura brasileira com o relógio da literatura universal. A ideia era superar o sentimento de atraso e a necessidade de uma identidade nacional; a antropofagia era uma metáfora para uma cultura que tinha como características a absorção e a transmutação constantes de modelos estrangeiros. O objetivo deste artigo é explorar os sentidos e ambiguidades que o primitivismo assumiu em alguns dos melhores momentos do modernismo de Oswald de Andrade em diálogo com a sua presença nas vanguardas europeias. - PALAVRAS-CHAVE - Primitivismo; Oswald
\end{abstract}

de Andrade; vanguarda. · ABSTRACT · Primitivism is a crucial feature of Brazilian modernism and it has in Oswald de Andrade's work one of its major expressions. The "pau brasil poetry" and "anthropophagy" resorted primitivism to, as Oswald de Andrade said, set the hands of Brazilian literature to the time of universal literature. The idea was to overcome the felling of delay and the necessity of a national identity; anthropophagy was a metaphor for a culture that was characterized by the persistent absorption and transmutation of foreign models. The aim of this paper is to explore the meanings and ambiguities that primitivism has assumed in some of the best moments of Oswald de Andrade's modernism also in dialogue with its presence in the European avantgardes. - KEYWORDS · Primitivism; Oswald de Andrade; avant-garde

Recebido em 6 de janeiro de 2016

Aprovado em I4 de julho de 2016

LIMA, Bruna Della Torre de Carvalho. Eles devoraram tudo: primitivismo, barbárie e as vanguardas. Revista do Instituto de Estudos Brasileiros, Brasil, n. 64, p. 296-309, ago. 2016.

DOI: http://dx.doi.org/Io.II606/issn.23I6-90IX.voi64p296-309

I Universidade de São Paulo (USP, São Paulo, SP, Brasil). 


\begin{abstract}
A horrível mixórdia de estilos e concepções do mundo do século passado mostrou-nos com tanta clareza aonde esses valores culturais podem nos levar, quando a experiência nos é subtraída, hipócrita ou sorrateiramente, que é hoje em dia uma prova de honradez confessar nossa pobreza. Sim, é preferível confessar que essa pobreza de experiência não é mais privada, mas de toda a humanidade. Surge assim uma nova barbárie. [...] Pobreza de experiência: não se deve imaginar que os homens aspirem a novas experiências. Não, eles aspiram a libertar-se de toda experiência, aspiram a um mundo em que possam ostentar tão pura e claramente sua pobreza externa e interna, que algo de decente possa resultar disso. Nem sempre eles são ignorantes ou inexperientes. Muitas vezes podemos afirmar o oposto: eles "devoraram" tudo, a "cultura" e os "homens" e ficaram saciados e exaustos (Walter Benjamin, "Experiência e pobreza", I933).
\end{abstract}

Em uma fórmula lapidar, que se tornou um emblema do movimento modernista, Oswald de Andrade parodiava Shakespeare e indagava: "Tupi or not tupi: that is the question” ${ }^{2}$. Além de brincar com a semelhança de sonoridade entre "to be" e "tupi”, o escritor reivindicava, através de uma língua estrangeira, a força criadora do primitivismo, visando positivar as peculiaridades brasileiras sem recair no pitoresco ou na valorização patrioteira dos dados locais. A questão dirigida ao leitor é provocativa: ao troçar com a referência erudita, o modernista ridiculariza o "lado doutor"3, a mania nacional de querer expressar erudição e cosmopolitismo por meio de citações consagradas. Com todos esses elementos juntos, Oswald "provincianiza" a indagação existencial de Hamlet ao substituir o "To be or not to be" pelo engraçado "Tupi or not tupi", transformando a questão ontológica em piada e expondo, com isso, a transmutação periférica do suposto universal.

No Brasil, a indagação existencial tem seu caráter local marcado pela referência aos índios Tupi, modelos diletos (e idealizados) do romantismo indianista do século

2 ANDRADE, Oswald de. Manifesto antropófago. In: SCHWARTZ, Jorge. Vanguardas latino-americanas: polêmicas, manifestos e textos críticos. São Paulo: Editora da Universidade de São Paulo, 2008, p. I74.

3 ANDRADE, Oswald de. (I924). Manifesto da Poesia Pau Brasil. In: SCHWARTZ, Jorge. Vanguardas latino-americanas: polêmicas, manifestos e textos críticos. São Paulo: Editora da Universidade de São Paulo, 2008. p. 166. 
XIX. Ao fragilizar o conteúdo filosófico da pergunta, trazido do céu à terra pela referência histórico-geográfica, a fórmula denuncia seu pretenso universalismo: no Brasil, nosso dilema moderno ainda remeteria ao período pré-cabralino. A frase condensa, dentre outros significados, o dilema que rondou a vida intelectual brasileira desde seus primórdios. A saber, o de como construir uma literatura, uma política, uma sociedade e uma cultura que pudessem reconhecer a si mesmas como originais, tendo como dado inicial o fato de que a condição colonial e periférica do país obrigava-o a se alimentar de modelos estrangeiros que muitas vezes pareciam não se aclimatar à realidade local. Oswald de Andrade, tencionando superar o sentimento de desajuste e de inferioridade advindo desse "problema da cópia", saiu-se com a antropofagia. Por sua vez, a antropofagia não dizia respeito apenas ao par local/global, mas trazia à baila um tema fundamental da vanguarda - a dialética entre a civilização e a barbárie - e ao fazê-lo incluía um capítulo brasileiro na história das vanguardas mundiais.

Como se sabe, as vanguardas se aclimataram de modo bastante particular ao Brasil e até hoje não estudamos o cubismo, o expressionismo ou o surrealismo brasileiro, mas aquilo que se convencionou chamar de "modernismo". No interior desse fenômeno, cuja generalidade confunde até os mais experientes especialistas, a obra de Oswald de Andrade apresenta-se, como vanguardista que é, como um problema literário ${ }^{4}$, pois consiste num trânsito entre os mais variados gêneros e as mais inusitadas formas: romance, drama, poesia, manifesto, ensaio filosófico, crítica literária e artigo jornalístico. E tal é a sua imbricação que escolher uma dessas formas é como puxar um fio de lã de uma meada que se reconfigura ao movimento de cada elemento do qual é composta. No entanto, é possível notar algumas permanências ao longo de sua obra integral que nos ajudam a percorrê-la como um todo, pois, se, por um lado, Oswald gostava de variar as formas, por outro, permanecia fiel a alguns temas, embora nunca deixasse de problematizá-los.

A noção de primitivismo é um desses temas e permite fazer uma ponte entre as vanguardas europeias e as brasileiras, auxiliando, assim, na compreensão do que foi esse "modernismo" de Oswald de Andrade de tão difícil classificação. O primitivismo é, assim, um elemento comum a ambas, e busca construir uma forma de expressão (ou de racionalidade) que supere alguns impasses culturais e históricos identificados pelas vanguardas.

As vanguardas do século XX, tanto na Europa, quanto na América Latina, fizeram do primitivismo um conceito polêmico. Os exemplos são inúmeros. Stravinsky, com a sua A sagração da primavera, de I9I3, evocava o sacrifício primitivo; Francis Picabia escreveu e musicou o Manifeste cannibale dans l'obscurité, lido por André Breton num espetáculo dadá de I920; e, no mesmo ano, em Paris, foi criada a revista Cannibale; Picasso revolucionou a pintura ocidental quando absorveu as formas encontradas nas máscaras tribais da África e da Oceania expostas no Musée d’Ethnographie du Trocadéro em Paris. Assim como as máscaras eram escudos que auxiliavam as pessoas a não cair sob influência dos maus espíritos, também na pintura de Picasso

4 CANDIDO, Antonio. (1945). Estouro e libertação. In: Brigada ligeira. Rio de Janeiro: Ouro sobre Azul, 2004 , p. 11. 
elas teriam um efeito exorcizante: tornariam essa pintura independente das amarras da tradição5.

Utilizado para marcar distância em relação a convenções do passado na Europa, o primitivismo consistiu numa busca de elementos originários da arte, naquilo que muitas vezes seria da ordem do inconsciente: nos sentimentos e na descarga de emoções "brutas", na simplicidade formal - fonte, para os cubistas, por exemplo, da possibilidade de uma expressão plástica pura, encontrada por eles na arte africana. Para Picasso, por exemplo, as máscaras Dan significavam renovação e vitalidade para a pintura moderna. Esse primitivismo era também uma utopia e um meio expressivo que as vanguardas contrapuseram à barbárie gerada pela civilização.

Na América Latina, a vanguarda era inseparável da noção de um mundo novo e de uma arte americana autêntica: Huidobro, em seu poema-programa "Arte poética" (I9I6), proclama a invenção de novos mundos; Mário de Andrade cria Macunaíma e o "matavirgismo"; Rivera e Mariatégui aproximam a cultura autóctone e a Revolução. O primitivismo, nesse caso, era também a proclamação de independência da cultura das ex-colônias.

Como descrito acima, é fato mais que conhecido que o primitivismo foi um tema muito presente nas vanguardas. Sendo assim, podemos nos perguntar: o que significou esse retorno ao primitivo num momento tão próspero do capitalismo e da chamada civilização ocidental? Este artigo buscará responder a essa pergunta através de um percurso pela obra de um dos nossos vanguardistas mais bárbaros: Oswald de Andrade.

Numa série de artigos, publicados originalmente no O Estado de S. Paulo em I953, um ano antes de sua morte, Oswald de Andrade escrevia:

Quem negará que Mussolini e Hitler, por mais abomináveis que tivessem sido, carregavam atrás de si uma massa desesperada de povo? E que eram essas camadas vulcânicas senão os enormes resíduos primitivistas, deixados propositadamente para trás, pelas classes "superiores e distintas" que usufruíam sozinhas os benefícios do capitalismo?

Oswald de Andrade não é o primeiro a relacionar nazismo e primitivismo. $\mathrm{O}$ encantamento das massas pelo líder fascista foi, com muita recorrência, associado a uma espécie de retorno à condição primitiva do homem 7 , embora diversos autores forneçam elementos para associarmos esse fenômeno não a um retorno ao homem

5 O depoimento de Picasso a respeito do encontro com a arte Africana pode ser encontrado em HUFFINGTON, Arianna Stassinopoulos. Picasso: creator and destroyer. New York: Simon and Shuster, I998.

6 ANDRADE, Oswald de. (I953). A marcha das utopias. In: A utopia antropofágica. 4. ed. São Paulo: Globo, $20 I I$ (Obras Completas de Oswald de Andrade). p. 279-280 (grifos meus).

7 Conferir HOBSBAWM, Eric J. (I959). Rebeldes primitivos: estudos sobre formas arcaicas de movimentos sociais nos séculos XIX e XX. Rio de Janeiro: Zahar, I970. 
primitivo $^{8}$, mas a um apogeu do homem civilizado'. A frase de Oswald de Andrade coloca uma proposição interessante, a saber, a de que esses "resíduos primitivistas" negados pela civilização resultariam em violência, em camadas vulcânicas que vez por outra voltam à tona no processo histórico.

Ainda no ensaio de I953, Oswald de Andrade assevera, então, que "a onda [primitivista] tomou conta do mundo atual, deste grande mundo do século XX que ainda se debate nas tenazes raivosas da reação por não ter levado às últimas consequências a certeza de sua alma primitiva. O que sobrenada, sobrenada no caos" ${ }^{\text {”o }}$. Esse ânimo primitivista das vanguardas foi percebido por ele como um grande pesadelo, sobretudo após a experiência das duas grandes guerras mundiais. Em seu romance Marco zero II - chão, de I945, encontramos a seguinte consideração: "A Antropofagia, sim, a Antropofagia só podia ter uma solução: Hitler! [...] Eles [os antropófagos] cantavam o bárbaro tecnizado! E que é o bárbaro tecnizado senão Hitler?”II

Mas, afinal, o que teria levado o autor da "Poesia Pau Brasil" e do "Manifesto antropófago" a associar a sua antropofagia ao nazismo? Para tentar compreender como Oswald de Andrade chegou a essa conclusão precisamos voltar no tempo até encontrar as primeiras leituras que o modernismo fez da antropofagia. O mundo assistia ao surgimento das primeiras tecnologias de destruição em massa: bombas, aviões, gases asfixiantes. E, ainda que não tenhamos vivenciado essa guerra na mesma proporção que os europeus e americanos, seus efeitos foram igualmente sentidos por aqui.

No ano de I9I7, Mário de Andrade escreveu, em Há uma gota de sangue em cada poema, "Os carnívoros", um poema sobre a guerra, do qual cito a última estrofe:

\author{
[...] Este é o trigo que é pão e alento \\ Vós que matastes com luxúria e sanha, \\ vinde buscar o prêmio: é o alimento... \\ Ei-lo: em raudal, em nuvem, em montanha! \\ Este é o trigo que nutre e revigora! \\ É para todos! Basta abrir as mãos! \\ Vinde buscá-lo!... - Vamos ver agora, \\ quem comerá a carne dos irmãos! $!^{\mathrm{I2}}$
}

8 Conferir FREUD, Sigmund. (I92I). Psicologia de grupo e análise do ego. Rio de Janeiro: Imago, I987; ADORNO, Theodor W. (I95I). Die Freudsche Theorie und die Struktur der faschistischen Propaganda. In: Gesammelte Schriften 8: Soziologische Schriften I. Frankfurt am Main: Suhrkamp, S. 408-433.

9 Conferir ADORNO, Theodor W.; HORKHEIMER, Max. (I947). Dialética do esclarecimento: fragmentos filosóficos. Tradução: Guido Antonio de Almeida. Rio de Janeiro: Jorge Zahar, I985.

Io ANDRADE, Oswald de. (I953). A marcha das utopias, op. cit., p. 28I.

II ANDRADE, Oswald de. (I945). Marco zero II: chão. 4. ed. São Paulo: Globo, I99I. (Obras Completas de Oswald de Andrade), p. 2Io.

I2 ANDRADE, Mário de. Obra imatura. Rio de Janeiro: Agir, 2009, p. 60. 
No poema, Mário denuncia a extrema violência da guerra, encarnada no retorno do homem à barbárie, através da antropofagia. Esse poema é de fundamental importância para que se note a ambiguidade que a inspiração primitivista apresentava para essas vanguardas: renovação e ao mesmo tempo barbárie. Há uma gota de sangue em cada poema tematiza a experiência da Primeira Guerra Mundial, numa mescla de deslumbramento e horror. O que interessa, aqui, é notar como foi essa situação que deu ensejo para que as vanguardas (não só na Europa) associassem a própria época a uma espécie de recaída do homem na barbárie, e vinculassem à noção de antropofagia a mesma contingência ${ }^{\mathrm{T3}}$. Essa barbárie nada tinha a ver com as sociedades primitivas, mas era um produto do mais intenso processo civilizatório.

É possível afirmar, nesse sentido, que as vanguardas modernistas indicam uma manifestação artística de um processo que vem de longe e que hoje se convencionou chamar de globalização, uma vez que, além de ter sido um fenômeno simultâneo em muitos lugares do mundo, compartilhou também temas e formas. Elas foram muito expressivas em toda a América Latina, nos Estados Unidos e na Europa ${ }^{\mathrm{I}}$. A mudança das formas e padrões de arte está, portanto, intimamente ligada à intensa experiência de civilização e de modernidade que o mundo viveu no início do século XX. Ainda que muito do que se constituiu como os padrões do nosso modernismo tenha sido importado da Europa, pela primeira vez na história do Brasil, aquilo que fazia sentido em matéria de arte (a fragmentação, a montagem, o caos) era experimentado na periferia de modo ainda mais intenso. Ou seja, São Paulo sofria uma espécie de "choque" de civilização. Como destaca o historiador Nicolau Sevcenko, "essa cidade que brotou súbita e inexplicavelmente, como um colossal cogumelo depois da chuva, era um enigma para seus próprios habitantes, perplexos, tentando entendê-lo como podiam, enquanto lutavam para não serem devorados"ז5.

Mas o primitivismo surgia também como o impulso renovador dessa civilização. Alguns artistas de vanguarda da Europa, por exemplo, foram buscar fora dela seus motivos e inspirações. Rimbaud foi ao Egito, Gauguin e Kandinsky foram para o Norte da África, Segall veio para o Brasil, Klee e Macke foram para a Tunísia, só para citar alguns exemplos. Como afirmou o vanguardista Mário de Micheli, "tudo o que era ‘bárbaro', tudo o que não era a Grécia clássica, ou a Renascença, ou a tradição a ela relacionada atraía com uma insólita violência"16. Para Oswald de Andrade, a Arte Moderna representava "um incrível destroçamento das boas maneiras do branco, adulto e civilizado":

I3 Conferir. ANCONA LOPEZ, Telê. Uma estreia retomada. In: ANDRADE, Mário de. Obra imatura. Rio de Janeiro: Agir, 2009.

I4 Conferir SARLO, Beatriz. Modernidade periférica: Buenos Aires I920 e I930. Tradução e posfácio: Júlio Pimentel Pinto. São Paulo: CosacNaify, 20Io; BÜRGER, Peter. Teoria da vanguarda. São Paulo: CosacNaify, 20Io; e SCHWARTZ, Jorge, op. cit.

I5 SEVCENKO, Nicolau. Orfeu extático na metrópole: São Paulo - sociedade e cultura nos frementes anos 20. São Paulo: Companhia das Letras, I992, p. 3 I.

I6 MICHELI, Mário de. (I959). Os mitos da evasão. In: . As vanguardas artísticas. São Paulo: Martins Fontes, 2004, p. 55 . 
O primitivo tremulava nos tapetes mágicos de Picasso, em Rouault, em Chirico que majestosamente criava o surrealismo. A estatuária negra do Benin figurava nas vitrines da Rue de La Boétie. Os ateliers eram trincheiras revolucionárias. [...]. A mecânica de Léger, a geometria que o cubismo passava ao abstracionismo, revelavam também as artes do primitivo que nada têm nem de paisagista nem de agricultor ${ }^{17}$.

Como é possível depreender do trecho acima, primitivismo significava muitas coisas ao mesmo tempo: exotismo (tapetes mágicos de Picasso), arte negra (estatuária negra do Benin $)^{18}$ e uma tentativa de encontrar uma linguagem virgem, uma espécie de redução da arte àquilo que é mais elementar (geometria que o cubismo passava ao abstracionismo).

Em seu “Manifesto da Poesia Pau Brasil”, lançado em I924, Oswald propunha, nessa mesma linha, o seguinte: "Nossa época anuncia a volta ao sentido puro. [...] Um quadro são linhas e cores. A estatuária são volumes sobre a luz”ı . A inspiração primitivista era generalizada. Em I924, Tristan Tzara destacava os elementos primitivos de Dada ${ }^{20}$ :

O Dada não é moderno. Assemelha-se mais a um retorno a uma religião quase budista de indiferença. [...] Na arte, o Dada reduz tudo a uma simplicidade inicial, tornando-se cada vez mais relativo. Mistura seus caprichos com o vento caótico da criação e as danças bárbaras das tribos selvagens ${ }^{2 \mathrm{I}}$.

Em I925, era inaugurada a Galerie Surréaliste, com a exposição de esculturas primitivas da Oceania pertencentes à coleção do surrealista André Breton ${ }^{22}$. O "novo mundo” ainda era uma grande novidade. Mas, como certa vez aferiu o próprio Oswald

I7 ANDRADE, Oswald de. (I953). A marcha das utopias, op. cit., p. 280.

I8 De acordo com Mário de Micheli, “Chamava-se ‘arte negra’ não apenas a escultura africana como a dos povos da Oceania, especialmente da Polinésia, de onde, com alguma frequência, os mercadores coloniais franceses traziam algumas peças em sua viagem de volta à pátria. Somente numa segunda fase começou-se a estabelecer uma diferença de origem e a detectar uma diferença de caráter entre as obras das diversas raças, regiões e tribos”. MICHELI, Mário de, op. cit., 2004, p. 56. Benin, atualmente República do Benin, foi colônia da França até I960. Ao que tudo indica é uma das muitas fontes dessa chamada “arte negra” que inspirou as vanguardas francesas nesse período.

I9 ANDRADE, Oswald de. (I924). Manifesto da Poesia Pau Brasil, op. cit., 20II, p. 64. Conferir também MANFIO, Diléa Zanotto. Poesias reunidas de Oswald de Andrade (edição crítica). Tese (Doutorado em Literatura Brasileira). Faculdade de Filosofia, Letras e Ciências Humanas, Universidade de São Paulo, I992.

20 O movimento Dada, formado por jovens em torno dos 20 anos - pelo ator e dramaturgo alemão Hugo Ball, pelo artista alsaciano Jean Arp, pelos romenos Tzara e Marvel Janco e pelo poeta alemão Richard Huelsen -, nasceu em I9I6 em Zurique e se espraiou para vários países da Europa no pós-Primeira Guerra Mundial (I9I4-I9I8).

2I TZARA, Tristan. (I924). Conferência sobre o Dada. In: CHIPP, Herschel Browning. (I988). Teorias da arte moderna. São Paulo: Martins Fontes, I996. (Coleção a), p. 39I.

22 Conferir CHIPP, Herschel Browning. Teorias da arte moderna. São Paulo: Martins Fontes, I996. (Coleção a), p. 39I. 
de Andrade, “o primitivismo que na França aparecia como exotismo era para nós, no Brasil, primitivismo mesmo" ${ }^{23}$. Tudo se passa como se o Brasil fosse primitivista avant la lettre. Como atestou Antonio Candido,

[...] não se ignora o papel que a arte primitiva, o folclore, a etnografia tiveram na definição das estéticas modernas, muito atentas aos elementos arcaicos e populares comprimidos pelo academicismo. Ora, no Brasil as culturas primitivas se misturam à vida cotidiana ou são reminiscências ainda vivas de um passado recente. As terríveis ousadias de um Picasso, um Brancusi, um Max Jacob, um Tristan Tzara, eram, no fundo, mais coerentes com a nossa herança cultural do que com a deles ${ }^{24}$.

Se, por um lado, o primitivismo, ou melhor, os primitivismos foram diferentes na Europa e na América Latina ${ }^{25}$, por outro, indicavam, num e noutro caso, a percepção generalizada de um "mal-estar na civilização" ou de uma crise da cultura, nos termos de Freud ${ }^{26}$. Nas palavras de Mário de Andrade,

[...] não aprecio a civilização, nem, muito menos, acredito nela. [...] Meu maior desejo é ir viver longe da civilização, na beira de algum rio pequeno na Amazônia, ou nalguma praia do mar do Norte brasileiro, entre gente inculta, do povo. Meu maior sinal de espiritualidade é odiar o trabalho, tal como ele é concebido, semanal e de tantas horas diárias, nas civilizações chamadas "cristãs"27.

Nessa chave, um dos temas principais das vanguardas pode ser formulado a partir da percepção de uma crise da civilização, da qual sairão tencionadas as noções de primitivismo e barbárie, o primeiro percebido como ímpeto de renovação da cultura ocidental, o segundo como seu produto imediato. Se pudéssemos constatar a presença de um novo código em arte criado pelas vanguardas - tomando o primitivismo como um desses códigos -, poderíamos assumir também que ele surge para comunicar alguma coisa, ainda que seja a impossibilidade da comunicação. Basta lembrar como Walter Benjamin associa à guerra essa derrota da razão em organizar o caos da experiência através da linguagem: "no final da guerra, observou-se que os combatentes voltavam mudos do campo de batalha não mais ricos, e sim mais pobres de experiência comunicável”28. A barbárie aparecia como a face de Janus da civilização.

23 Depoimento concedido a Péricles Eugênio da Silva Ramos no Correio Paulistano, 26/6/1949.

24 CANDIDO, Antonio. (I965). Crítica e sociologia. In: . Literatura e sociedade: estudos de teoria e história literária. Io. ed. revista pelo autor. Rio de Janeiro: Ouro sobre Azul, 2008, p. I44.

25 Conferir SCHWARTZ, Jorge, op. cit.

26 Conferir BÜRGER, Peter, op. cit.

27 ANDRADE, Mário de. Entrevistas e depoimentos. São Paulo: T. A. Queiroz Editora, I983, p. 39 e 4I.

28 BENJAMIN, Walter. (I936). O narrador: considerações sobre a obra de Nikolai Leskov. In: Magia e técnica, arte e política: ensaios sobre literatura e a história da cultura. São Paulo: Brasiliense, I994. (Obras Escolhidas - v. I), p. I98. 
No caso do Brasil, a sensação era a de que uma nova fase surgia, e era como se as vanguardas, Mário e Oswald de Andrade em particular, sentissem a necessidade e o chamado para a construção de uma cultura à altura desse novo projeto. Por isso mesmo, os modernistas iam à caça daquilo que poderia constituir seus fundamentos ${ }^{29}$. Numa visão um tanto romântica, Mário e Oswald de Andrade fizeram um elogio de nossa preguiça e de nosso ócio. Dela são testemunhas o egrégio mote "Ai que preguiça..." ${ }^{30}$ do personagem da rapsódia que leva seu nome no título, Macunaíma ${ }^{31}$, e a declaração de Oswald de Andrade de que "O Brasil foi apenas a profecia e o horizonte utópico do ócio”32.

O primitivismo, neste caso, tem sentido construtivo e inaugural. O mesmo Mário de Andrade afirmou: "Eu sei que sou primitivo, porém já falei em que sentido o sou. Sou primitivo porque sou indivíduo duma fase principiando"33. Oswald de Andrade se aproximaria do diagnóstico de Mário:

No Brasil andam aos pontapés Civilização e Cultura. Da Civilização nos refastelamos no pior. E da Cultura que há quatro séculos procura dar-nos um caráter de povo lírico, cordial e estoico destruímos implacavelmente as sobras, liquidando o índio, sofisticando o negro e monogamizando o português ${ }^{34}$.

Para os dois modernistas haveria certa incompatibilidade entre a civilização ocidental e a nossa cultura, avessa ao trabalho capitalista, cordial e estoica, de modo que o primitivismo poderia ser entendido também como aquilo que fornece a possibilidade de sermos o que já somos ${ }^{35}$. Porém, esse primitivismo permanecia como um impulso renovador. Numa entrevista de I928, data da criação da "antropofagia", Oswald de Andrade defendia que certa realidade social primitiva experimentada no

29 Conferir RIBEIRO, Monica Cristina. Arqueologia modernista: viagens e reabilitação do primitivo em Mário e Oswald de Andrade. Dissertação de (Mestrado em Antropologia Social). Instituto de Filosofia e Ciências Humanas, Universidade Estadual de Campinas, 2005.

30 ANDRADE, Mário de. (I928). Macunaíma: o herói sem nenhum caráter. Edição crítica de Telê Porto Ancona Lopez. Rio de Janeiro: Livros Técnicos e Científicos; São Paulo: Secretaria da Cultura, Ciência e Tecnologia, I978. 3I De acordo com Carlos Ornelas Berriel, "Mário de Andrade afirma nesta circunstância a tese do 'ócio criador', isto é, a tese de que a cultura e a civilização brasileiras, se afirmadas, o seriam pelo ócio e não pelo trabalho - por este ser uma característica da civilização europeia”. BERRIEL, Carlos Eduardo Ornelas. Dimensões de Macunaíma: filosofia, gênero e época. Dissertação (Mestrado em Teoria Literária). Instituto de Estudos da Linguagem, Universidade Estadual de Campinas, I987, p. 9I. Conferir também MELLO E SOUZA, Gilda de. (I979). O tupi e o alaúde. São Paulo: Editora 34, 2003.

32 ANDRADE, Oswald de. (I953). A marcha das utopias, op. cit., p. 282.

33 ANDRADE, Mário de. Carta a Tristão de Athayde. Citado por FONSECA, Maria Augusta. Taí: é e não é cancioneiro Pau Brasil. Literatura e sociedade, n. 7, 2003-2004, p. I23.

34 ANDRADE, Oswald de. Estética e política. Pesquisa, organização, introdução, notas e estabelecimento do texto: Maria Eugenia Boaventura. São Paulo: Globo, I992. (Obras Completas de Oswald de Andrade), p. 203-204. 35 Sobre o primitivismo em Oswald de Andrade, conferir FONSECA, Maria Augusta. Taí: é e não é - cancioneiro Pau Brasil. In: Literatura e sociedade, n. 7, 2003-2004, p. I20-I37. 
Brasil poderia servir de modelo para essa crise da civilização e da cultura percebida na Europa após a guerra.

Sob um tom de paradoxo e violência, a antropofagia poderá quem sabe dar à própria Europa a solução do caminho ansioso em que ela se debate. Note você como a Europa procura se primitivar. Aí estão todos os grandes movimentos para prova-lo. [...] Leia-se ou Freud ou Bergson ou Conué ou Keyserling ou Spengler ou Bertrand Russell, examine-se quaisquer tendências coletivistas - Dada, Futurismo, Surrealismo, Expressionismo -, e salta aos olhos uma ávida repugnância por toda a milenária idolatria de ordem religiosa intelectual e moral que a guerra começou a estorvar ${ }^{36}$.

No “Manifesto antropófago”, Oswald de Andrade identificava também o primitivismo, no sentido indígena do termo, com o nascimento de uma nova utopia que ressoou na Europa após a descoberta das Américas: "Sem nós a Europa não teria sequer a sua pobre declaração dos direitos do homem"37. O modernista, que citava Rousseau e Montaigne em seu famoso Manifesto, tinha consciência do choque que o contato com os chamados povos primitivos havia produzido na Europa. Numa entrevista dada em I947, Oswald enfatiza como nomes, livros e ideias que abriram caminho para a nova civilização: "os enciclopedistas, Montaigne e Rousseau, na reabilitação primeira do homem primitivo" 38 . E afirma que sua antropofagia de I928 saiu de "Des cannibales" dos Essais de Montaigne. É por esta razão que Oswald de Andrade infere que, sem nós, não haveria a Declaração dos Direitos do Homem. Para o modernista, a revolução que a descoberta de um homem diverso do europeu causou foi tal, que chegou a modificar toda a concepção ocidental de homem, oferecendo ao mundo uma nova utopia. Nos anos I950, ele retomaria esta tese. Em A Marcha das utopias (I953), Oswald esclarece esta ideia:

A Geografia das Utopias situa-se na América. [...] A não ser A República de Platão, que é um estado inventado, todas as Utopias que vinte séculos depois apontam no horizonte do mundo moderno e profundamente o impressionam, são geradas da descoberta da América. O Brasil não fez má figura nas conquistas sociais do Renascimento. [...] E minha fé no Brasil vem da configuração social que ele tomou, modelado pela civilização jesuítica em face do calvinismo áspero e mecânico que produziu o capitalismo da América do Norte ${ }^{39}$.

A utopia de igualdade que serviu à Europa, para Oswald de Andrade, advinha do

36 ANDRADE, Oswald de. (I928). Contra os “emboabas”. In: Os dentes do dragão: entrevistas. Pesquisa, organização e introdução: Maria Eugenia Boaventura. São Paulo: Globo/Secretaria de Estado da Cultura, I99o, p. 4I.

37 ANDRADE, Oswald de. (I928). Manifesto antropófago, op. cit., p. I75.

38 ANDRADE, Oswald de. (I947). O êxito na terra substituiu a esperança no céu, op. cit., p. 2III.

39 ANDRADE, Oswald de. (I953). A marcha das utopias, op. cit., p. 226. 
"matriarcado de Pindorama”"40 e do "Brasil Caraíba", e tinha inspiração fortemente rousseauniana ${ }^{4 \mathrm{I}}$. Oswald de Andrade toma esse homem selvagem, tal como o fez Rousseau, antes como um conceito, uma utopia; algo que nunca teve lugar ou existência efetiva na história. Na verdade, essa "representação" dos índios produzida na longa duração, e a partir de uma literatura de viajantes, encontrou neles fonte de inspiração para construir uma visão idílica de uma sociedade melhor. Aliás, essa inspiração é muito presente em ambos os autores: Rousseau afirma que "o homem que medita é um animal depravado" 42 e no "Manifesto" encontramos: "Suprimamos as ideias e outras paralisias" na cultura ocidental, que estaria perdendo autenticidade com o desenvolvimento da civilização. Ou seja, haveria uma intelectualização excessiva da cultura que a levaria a enrijecer-se, a petrificar-se: "O stop do pensamento que é dinâmico"\$4.

$\mathrm{Na}$ Europa, a sensação era de uma civilização devastada pela guerra. O primitivismo, nesse caso, poderia, então, fornecer um novo caminho para o futuro, uma nova proposta de racionalidade. A percepção, tal como em Mário e Oswald de Andrade, era a de que a civilização provinha de uma experiência no mínimo decepcionante e cujas bases pareciam se desfazer.

A antropofagia defendida por Oswald de Andrade na década de I920 consistia num esforço de formulação de uma cultura brasileira original que não se estruturava em torno do conceito de identidade. Ao contrário, buscava utilizar a prática antropofágica primitiva para superar a decadência de uma cultura que havia expulsado de si tudo aquilo que dissesse respeito ao não idêntico.

Tal como afirmou Oswald de Andrade, "o que sobrenada, sobrenada no caos"45, e havia algo na ideia de primitivismo que dava um lugar àquilo que vinha sendo ignorado pela civilização, para essa força cega que reapareceria como uma espécie

40 Para o modernista, a sociedade ideal deve ocorrer sob a égide do matriarcado.

4I Como inferiu Benedito Nunes, “Quanto à sua ideologia, o 'antropófago' é parente consanguíneo, pelo lado do homem natural, do bom selvagem. Este, ao contrário do animal feliz da interpretação errônea corrente, já é o primitivo socializado de Rousseau, no Discours sur l'origine et les fondements de l'inegalité parmi les hommes, que conseguira viver num estado de equilíbrio, entre Cultura e Natureza, na fímbria da sociedade política nascente, onde a piedade e o amor-próprio se contrabalançavam, porque aí não havia nem propriedade privada da terra nem concentração do poder no Estado". NUNES, Benedito. (I972). A antropofagia ao alcance de todos. In: ANDRADE, Oswald de. A utopia antropofágica. 4. ed. São Paulo: Globo, 20II. (Obras Completas de Oswald de Andrade). p. 37 .

42 ROUSSEAU, Jean Jacques. (I755). Discurso sobre a origem e os fundamentos da desigualdade entre os homens. In: . Do contrato social; Ensaio sobre a origem das línguas; Discurso sobre a origem e os fundamentos da desigualdade entre os homens; Discurso sobre as ciências e as artes. 3. ed. São Paulo: Abril Cultural, I983. (Os Pensadores). p. 24I.

43 Oswald de Andrade. (I928). Manifesto antropófago, op. cit., p. I79. Esse é um dos momentos da obra de Oswald de Andrade que apresentam certo elogio ao irracionalismo que, posteriormente, permitiu a leitura de toda a sua obra dessa maneira.

44 Ibidem, p. I76.

45 ANDRADE, Oswald de. (I953). A marcha das utopias, op. cit., p. 28I. 
de retorno do recalcado e alcançaria seu grau máximo nos campos de concentração nazistas.

Esse longo século XX foi marcado por uma série de experiências traumáticas, e as vanguardas artísticas muitas vezes as predisseram, tematizaram e buscaram resistir a elas ${ }^{46}$. Sem dúvida o chamado vanguardismo, no sentido amplo do termo, foi um fenômeno complexo e cheio de contradições. Esse século havia revelado o péssimo hábito que têm as utopias de se realizarem às avessas, de se tornarem distopias. E essa é uma das razões que podem explicar o modo como Oswald de Andrade associa o primitivismo à experiência do nazismo, no final de sua vida. A decepção com as utopias e a percepção de que o primitivismo reclamado pelas vanguardas 47 era uma faca de dois gumes implicaram uma revisão de sua antropofagia.

A contraparte desse processo estava nos elementos emancipatórios trazidos pelo progresso industrial: seu potencial de fazer ruir a tradição, suas pretensões democráticas e a crise da ordem burguesa, que em São Paulo tomou a forma da derrocada da elite cafeeira. No âmbito geral, é essa contradição que Oswald de Andrade procurou trabalhar. Ou seja, a principal fonte social da ambiguidade da obra do modernista consiste na oscilação - própria das vanguardas - entre o entusiasmo com o progresso e a crítica de seus limites, expressos por Oswald através da tentativa de despolarização do local/universal. As vanguardas estão sempre andando, elas também, nessa corda bamba, o que fica patente e visível na noção de primitivismo.

SOBRE A AUTORA

BRUNA DELLA TORRE DE CARVALHO LIMA é doutoranda na Universidade de São Paulo, Faculdade de Filosofia, Letras e Ciências Humanas/Departamento de Sociologia/Visiting Scholar at Duke University/ Literature Department. Atualmente é bolsista da Coordenação de Aperfeiçoamento de Pessoal de Nível Superior - Capes.

E-mail: bru.dellatorre@gmail.com

\section{REFERÊNCIAS BIBLIOGRÁFICAS}

ADORNO, Theodor W. (I95I). Die Freudsche Theorie und die Struktur der faschistischen Propaganda. In: . Gesammelte Schriften 8: Soziologische Schriften I. Frankfurt am Main: Suhrkamp, S. 408-433, I95I.

46 De certo modo isso é uma generalização um pouco extremada, pois sabemos que muitos vanguardistas apoiaram os regimes totalitários, como é o caso, por exemplo, de Marinetti. Busco apenas ressaltar como há uma história da arte ligada às experiências intensas desse século que, principalmente após a Segunda Guerra Mundial, alcançaram em cheio o coração da América Latina.

47 Conferir BÜRGER, Peter, op. cit. 
ADORNO, Theodor W.; HORKHEIMER, Max. (I947). Dialética do esclarecimento: fragmentos filosóficos. Tradução: Guido Antonio de Almeida. Rio de Janeiro: Jorge Zahar, I985.

ANCONA LOPEZ, Telê. Uma estreia retomada. In: ANDRADE, Mário de. Obra imatura. Rio de Janeiro: Agir, 2009.

ANDRADE, Mário de. (I928). Macunaíma: o herói sem nenhum caráter. Edição crítica de Telê Porto Ancona Lopez. Rio de Janeiro: Livros Técnicos e Científicos; São Paulo: Secretaria da Cultura, Ciência e Tecnologia, I978.

. Entrevistas e depoimentos. São Paulo: T. A. Queiroz, I983.

. Carta a Tristão de Athayde. Citado por Maria Augusta Fonseca. Taí: é e não é - cancioneiro Pau Brasil. Literatura e sociedade, n. 7, 2003-2004, p. I20-I37.

. Obra imatura. Rio de Janeiro: Agir, 2009.

ANDRADE, Oswald de. (I928). Contra os “emboabas”. In: Os dentes do dragão: entrevistas. Pesquisa, organização e introdução: Maria Eugenia Boaventura. São Paulo: Globo/Secretaria de Estado da Cultura, I990, p. $59-63$.

. (I947). O êxito na terra substituiu a esperança no céu. In: Os dentes do dragão: entrevistas. Pesquisa, organização e introdução: Maria Eugenia Boaventura. São Paulo: Globo/Secretaria de Estado da Cultura, I990, p. 20I-2I8.

. (I945). Marco zero II: chão. 4. ed. São Paulo: Globo, I99I. (Obras Completas de Oswald de Andrade). . Estética e política. Pesquisa, organização, introdução, notas e estabelecimento do texto: Maria Eugenia Boaventura. São Paulo: Globo, I992. (Obras Completas de Oswald de Andrade).

. (I928). Manifesto antropófago. In: SCHWARTZ, Jorge. (I995). Vanguardas latino-americanas: polêmicas, manifestos e textos críticos. São Paulo: Editora da Universidade de São Paulo, 2008, p. I42-I47. . (I924). Manifesto da Poesia Pau Brasil. In: SCHWARTZ, Jorge. (I995). Vanguardas latino-americanas: polêmicas, manifestos e textos críticos. São Paulo: Editora da Universidade de São Paulo, 2008, p. I36-I39.

. (I953). A marcha das utopias. In: A utopia antropofágica. 4. ed. São Paulo: Globo, 20II. (Obras Completas de Oswald de Andrade), p. I6I-209.

BENJAMIN, Walter. Experiência e Pobreza. (I933). In: . Magia e técnica, arte e política: ensaios sobre literatura e a história da cultura. São Paulo: Brasiliense, I994, p. ПI4-II9. (Obras Escolhidas - v. I). . (I936). O narrador: considerações sobre a obra de Nikolai Leskov. In: . Magia e técnica, arte $e$ política: ensaios sobre literatura e a história da cultura. São Paulo: Brasiliense, I994, p. I97-22I. (Obras Escolhidas - v. I).

BERRIEL, Carlos Eduardo Ornelas. Dimensões de Macunaíma: filosofia, gênero e época. Dissertação (Mestrado em Teoria Literária). Instituto de Estudos da Linguagem, Universidade Estadual de Campinas, I987.

BÜRGER, Peter. (I974). Teoria da vanguarda. São Paulo: CosacNaify, 2010.

CANDIDO, Antonio. (I945). "Estouro e libertação”. In . Brigada ligeira. Rio de Janeiro: Ouro sobre Azul, 2004, p. II-30. . (I965). “Crítica e sociologia”. In: . Literatura e sociedade: estudos de teoria e história literária. Io. ed. revista pelo autor. Rio de Janeiro: Ouro sobre Azul, 2008, p. I3-26.

CHIPP, Herschel Browning. (I988). Teorias da arte moderna. São Paulo: Martins Fontes, I996. (Coleção a). FONSECA, Maria Augusta. Taí: é e não é - cancioneiro Pau Brasil. Literatura e sociedade, n. 7, 2003-2004, p. I20-I37.

FREUD, Sigmund. (I92I). Psicologia de grupo e análise do ego. Rio de Janeiro: Imago, I987. 
HOBSBAWM, Eric J. (1959). Rebeldes primitivos: estudos sobre formas arcaicas de movimentos sociais nos séculos XIX e XX. Rio de Janeiro: Zahar, I970.

HUFFINGTON, Arianna Stassinopoulos. Picasso: creator and destroyer. New York: Simon and Shuster, I998.

MANFIO, Diléa Zanotto. Poesias reunidas de Oswald de Andrade (edição crítica). Tese (Doutorado em Literatura Brasileira). Faculdade de Filosofia, Letras e Ciências Humanas, Universidade de São Paulo, I992.

MELLO E SOUZA, Gilda de. (I979). O tupi e o alaúde. São Paulo: Editora 34, 2003.

MICHELI, Mário de. (I959). Os mitos da evasão. In: . As vanguardas artísticas. São Paulo: Martins Fontes, 2004.

NUNES, Benedito. (I972). A antropofagia ao alcance de todos. In: ANDRADE, Oswald de.

A utopia antropofágica. 4. ed. São Paulo: Globo, 20II, p. 5-8. (Obras Completas de Oswald de Andrade).

RIBEIRO, Monica Cristina. Arqueologia modernista: viagens e reabilitação do primitivo em Mário e Oswald de Andrade. Dissertação (Mestrado em Antropologia Social). Instituto de Filosofia e Ciências Humanas da Universidade Estadual de Campinas, Universidade de Campinas, 2005.

ROUSSEAU, Jean Jacques. (I755). Discurso sobre a origem e os fundamentos da desigualdade entre os homens. In: . Do contrato social; Ensaio sobre a origem das línguas; Discurso sobre a origem e os fundamentos da desigualdade entre os homens; Discurso sobre as ciências e as artes. 3. ed. São Paulo: Abril Cultural, I983. (Os Pensadores).

SARLO, Beatriz. (I988). Modernidade periférica: Buenos Aires I920 e I930. Tradução e posfácio: Júlio Pimentel Pinto. São Paulo: CosacNaify, 2010.

SEVCENKO, Nicolau. Orfeu extático na metrópole: São Paulo - sociedade e cultura nos frementes anos 20. São Paulo: Companhia das Letras, I992.

SCHWARTZ, Jorge. (1995). Vanguardas latino-americanas: polêmicas, manifestos e textos críticos. São Paulo: Editora da Universidade de São Paulo, 2008.

TZARA, Tristan. (1924). Conferência sobre o Dada. In: CHIPP, Herschel Browning. (I988). Teorias da arte moderna. São Paulo: Martins Fontes, I996. (Coleção a). 